VARIA

\title{
Firmas y rúbricas de judeoconversos de la compañía de arrendadores Coronel-Alcalá
}

Efrén de la Peña Barroso

Sección Nobleza, Archivo Histórico Nacional (Toledo)

Pese a que los miembros judeoconversos de la compañía de arrendadores Coronel-Alcalá tuvieron una singular relevancia en la Castilla de finales del siglo XV, aún no había sido publicado ningún documento con sus firmas y rúbricas. El trabajo sobre diferentes fondos archivísticos ha permitido al autor de este artículo estudiar los signos de validación, verdaderas marcas de identidad, utilizados por algunos de sus miembros en sus operaciones financieras.

Palabras ClaVE: cultura notarial; judíos; conversos; firmas; arrendamientos fiscales; Castilla; siglo XV.

Signatures of New Christian Members of the Revenue Collection Enterprise of CoronelAlcalá.- Though some of the New Christian members of the Coronel-Alcalá revenue collection enterprise were high ranking converts in $15^{\text {th }}$ century Castile, their signatures and seals had not yet been identified and published. The research of the author in several archival repositories has allowed him to locate the signatures of some of these tax-collectors. These signatures -veritable identity marks- were used by them to validate their financial operations.

Keywords: Notarial Culture; Jews; New Christians; Signatures; Revenue Collection; Castile; $15^{\text {th }}$ Century.

La compañía de arrendadores formada por don Abraham Seneor (convertido bajo el nombre de Fernán Pérez Coronel), Mayr Melamed (también convertido y bautizado como Fernán Núñez Coronel) y Luis de Alcalá fue, sin duda alguna, la más importante de las que operaron en la Corona de Castilla durante el último cuarto del siglo XV. Su actividad económica y la trayectoria personal de sus componentes han sido puestas de relieve en los últimos

\footnotetext{
*efren.dlp@mcu.es
} 
años por diferentes investigadores '. Sin embargo, todavía no se había hecho referencia a los elementos gráficos que permitieron validar legalmente todas sus operaciones financieras: las firmas y las rúbricas de los miembros de la compañía ${ }^{2}$.

En el Diccionario de la Lengua Española de la Real Academia Española se define 'firma' como el «nombre y apellido, o título, que una persona escribe de su propia mano en un documento, para darle autenticidad o para expresar que aprueba su contenido», que quiere decir que la firma se realiza para validar y autenticar el texto del documento. El mismo diccionario define 'rúbrica' como «rasgo o conjunto de rasgos de forma determinada que como parte de la firma pone cada cual después de su nombre o título, y que a veces va sola, esto es, no precedida del nombre o título de la persona que rubrica».

No obstante, a finales del siglo XV los significados de 'firma' y 'rúbrica' no eran los actuales. Los documentos medievales se validaban con la firma de las partes actuantes, del notario y de los testigos, según las cláusulas corroborativas del tipo «e firmáronlo de sus nonbres», aunque en realidad ese concepto de 'firma' fusionaba las dos acepciones anteriores. De hecho, Sebastián de Covarrubias todavía definía el término 'firma' a comienzos del siglo XVII como «la rúbrica, inscripción y nombre escrito de propia mano, que haze firme todo lo contenido y escrito encima de la firma» ${ }^{3}$; mientras que 'rúbrica' era definida como «la inscripción de los títulos del derecho. Díxose assí porque se escrive con letra colorada para diferenciarse de la demás escritura» ${ }^{4}$.

${ }^{1}$ El funcionamiento de la compañía ha sido estudiado por C. Álvarez GARCía, «Los judíos y la hacienda real bajo el reinado de los Reyes Católicos. Una compañía de arrendadores de rentas reales, en Las Tres Culturas en la Corona de Castilla y los sefardíes (Salamanca 1990), págs. 87125; Y. Moreno Koch, «Diez años de actividad económica en el reinado de los Reyes Católicos: Rabí Meir Melamed (Fernán Núñez Coronel)», en A. Meyuhas Ginio, C. Carrete Parrondo (coords.), Creencias y Culturas (Salamanca 1998), págs. 159-168; y M.-A. LADERo QueSADA, «La receptoría y pagaduría general de la Hacienda regia castellana entre 1491 y 1494: de Rabí Meír Melamed a Fernán Núñez Coronel», En la España Medieval 25 (2002), págs. 425-506.

${ }^{2}$ Ya ha sido reproducida la firma de otro notable judío castellano en el artículo de F. CANTERA Burgos, «Los repartimientos de rabí Jacó Abén Nuñes», Sefarad 31 (1971), págs. 213-249 (ilustración con la firma de rabí Jacó Abén Nuñes entre págs. 214-215), aunque el autor no se ocupó de su estudio. Unas interesantes notas sobre la grafía de este mismo apellido las publicó J. Castaño, «Social Networks in a Castilian Aljama and the Court Jews in the Fifteenth Century: A Preliminary Survey (Madrid 1445-1475)», En la España Medieval 20 (1997), págs. 377-390: 383, n. 17.

${ }^{3}$ S. de Covarrubias, Tesoro de la lengua castellana o española (Barcelona 1993), pág. 596 (s.v. 'firma').

\footnotetext{
${ }^{4}$ Covarrubias, Tesoro, pág. 916 (s.v. 'rúbrica').
} 
En definitiva, no cabe duda de que, aunque la firma fuese el principal elemento de validación del documento, la parte más original de la suscripción estaba constituida por la rúbrica, por cuanto su mayor o menor complejidad suponía la verdadera seña de identidad de su autor. En una época en la que todos los escribanos utilizaban la letra cortesana en sus escritos, la personalización de la rúbrica cobraba aún más importancia en la creación de una marca personal que fuese reconocible por el destinatario del documento.

\section{Las suscripciones de los miembros de la compañía}

El hallazgo de varios documentos firmados y rubricados por los miembros de esta compañía de arrendadores ha permitido reproducir y valorar sus signos gráficos en detalle ${ }^{5}$. El elenco de autógrafos que presentamos a continuación lo componen, en este orden, las firmas y rúbricas de Abraham Seneor-Fernán Pérez Coronel, de Fernán Núñez Coronel, y de Luis de Alcalá. Los tres arrendadores estuvieron asociados entre los años 1473 y 1494, el período de desarrollo y auge de la compañía. Sin embargo, también contaron con el apoyo de otros arrendadores en distintas etapas de su existencia. Es el caso de los hermanos Vidal y Abraham Bienveniste, asociados a Abraham Seneor entre 1473 y $1485^{\circ}$, o el de don Isaac Abravanel y su yerno Yucé Abravanel, que ocuparon el hueco dejado por los anteriores y que participaron en los negocios de la compañía durante los años anteriores a la expulsión ? . Puesto que no hemos conseguido localizar documentos firmados por los miembros «no permanentes» tendremos que conformarnos con la documentación rubricada por los miembros principales.

Don Abraham Seneor es el personaje más conocido de todos los que integraron la compañía. Último juez mayor de las aljamas castellanas, y con una personalidad no exenta de polémica entre sus contemporáneos, gozó de la protección real por haber jugado un papel primordial en 1473, junto con Andrés de Cabrera, en la reconciliación de Enrique IV con su hermana Isabel. Quizá esto le sirvió para catapultarse a nivel político y económico, llegando a convertirse en pocos años en uno de los judíos más adinerados de toda la Corona con una hacienda valorada en torno a cinco millones de maravedíes ${ }^{8}$.

${ }^{5}$ Debo agradecer a Antonio Martín Rodríguez, técnico en fotografía e imagen, la ayuda prestada para tratar digitalmente las imágenes que se aquí se reproducen.

${ }^{6}$ Álvarez García, «Los judíos y la Hacienda Real», pág. 96.

${ }^{7}$ Álvarez García, «Los judíos y la Hacienda Real», pág. 97.

${ }^{8}$ Álvarez García, «Los judíos y la Hacienda Real», pág. 93. 
Abraham Seneor firmaba con su nombre escrito en castellano («Abrahén»), y debajo su mismo nombre en caracteres hebreos cursivos (אברהם, 'Abraham') . No deja de ser curioso que su nombre se escribiese de forma diferente en castellano («Abrahén») y en hebreo («Abraham»), lo que podría deberse a la transliteración fonética en castellano de los sonidos hebreos.

Su rúbrica se componía de tres lóbulos alargados situados a la izquierda de la firma, el del medio más largo y el de la derecha abierto en su base. Bajo estos lóbulos el autor realizaba diversos bucles. A la derecha del nombre, Abraham Seneor realizaba un símbolo similar al de una clave musical. Bajo la firma y la rúbrica el autor trazaba una línea oblicua:

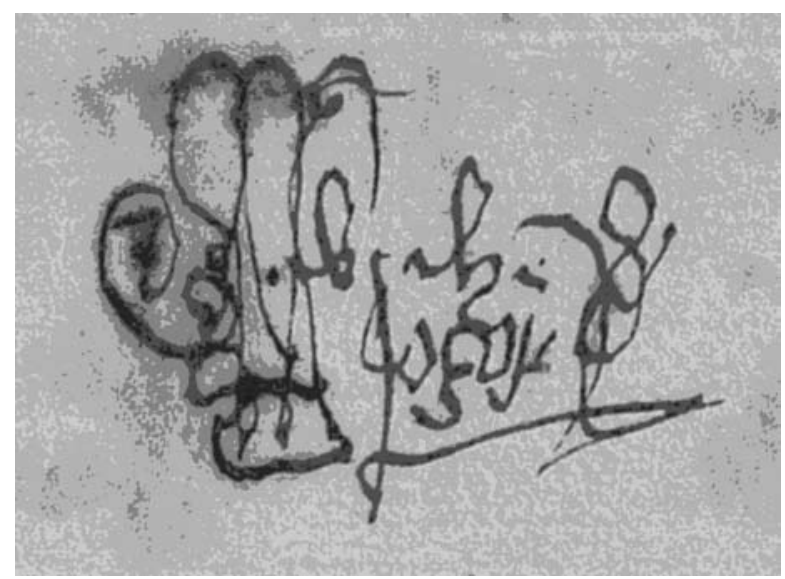

Fig. 1: Firma y rúbrica de Abraham Seneor ${ }^{10}$.

El Cronicón de Valladolid recoge que Abraham Seneor se convirtió al cristianismo el 15 de junio de 1492 en Guadalupe y que fue apadrinado por los reyes, recibiendo el nombre de Fernán Pérez Coronel ${ }^{11}$. Una vez convertido modificó

${ }^{9}$ Agradezco a Yolanda Moreno Koch y a Ricardo Muñoz Solla su ayuda en la transcripción de los caracteres hebreos de esta firma.

${ }^{10}$ La firma y la rúbrica de Abraham Seneor aparece en España, Ministerio de Cultura, Sección Nobleza, Archivo Histórico Nacional (en adelante, SN, AHN), Osuna, caja 3913, doc. 7, fechado en Valladolid el 11 de noviembre de 1488, que trata del pago realizado por Abraham Seneor a Francisca de Tapia, heredera de su hermano Diego de Tapia, de 8.000 maravedíes situados en ciertas rentas de Segovia y su Tierra.

${ }^{11}$ Doctor de Toledo, Cronicón de Valladolid (1333-1539) (Valladolid 1984), pág. 195. Los reyes estuvieron en Guadalupe desde el día 11 hasta, al menos, el 20 de junio de 1492. 
su firma debido a su cambio de nombre («Fernand Peres»), y también cambió levemente su rúbrica: el lóbulo abierto ahora se cierra y cambia la forma del bucle de la derecha de la firma. Ahora bien, debido a su avanzada edad de entre 80 y 90 años ${ }^{12}$, los trazos de su autógrafo ya no son tan limpios como en el caso anterior, sino que responden a los de un hombre de pulso trémulo y gastado por la edad.

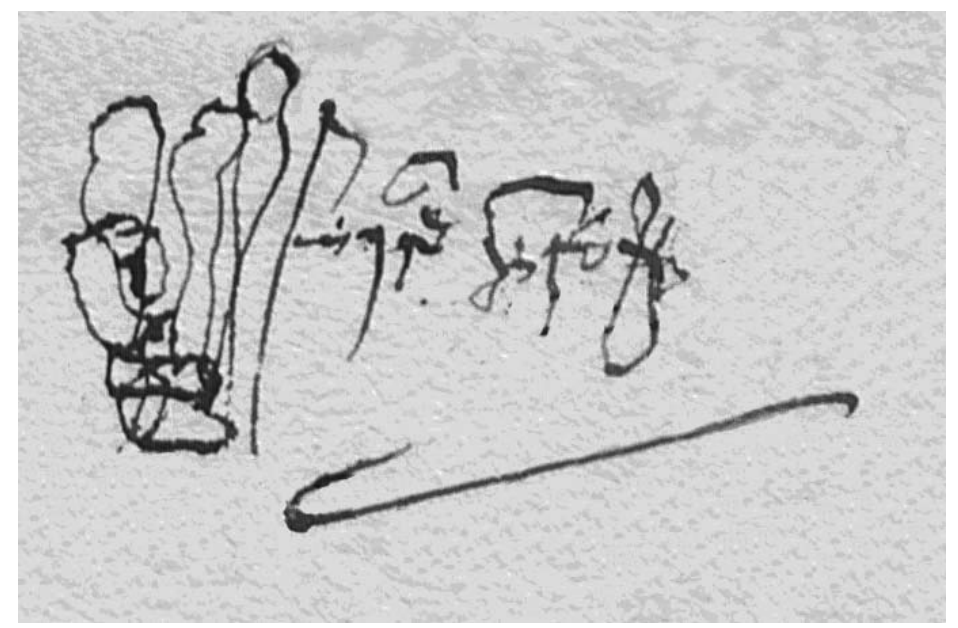

Fig. 2: Firma y rúbrica de Fernán Pérez [Coronel] ${ }^{13}$.

El segundo miembro en importancia de la famosa compañía de arrendadores se llamaba Mayr Melamed. Originario quizá de tierras abulenses, casó en

Para conocer su itinerario sigue siendo fundamental A. RUMEU DE ARMAS, Itinerario de los Reyes Católicos (1474-1516) (Madrid 1974), págs. 194-195. Sería deseable que se realizase un estudio acerca de los motivos por los que los judíos convertidos recibían determinados nombres y patronímicos; véase, entretanto, A. Blasco Martínez, «Hagionomástica en judeoconversos aragoneses», Memoria Ecclesiae 24 (2004), págs. 121-144, donde estudia la preferencia de numerosos conversos aragoneses por onomástica de carácter sagrado.

${ }^{12}$ C. CARrete Parrondo, «R. Abraham Seneor (Fernán Pérez Coronel): conjeturas tradicionales y realidad documental», Sefarad 46 (1986), págs. 111-121: 118; M.-A. LADERo QueSADA, «La receptoría y pagaduría general», pág. 430, n. 10; e IDEM, «Coronel, 1492: de la aristocracia judía a la nobleza cristiana en la España de los Reyes Católicos», BRAH 200 (2003), págs. 11-24: 12.

${ }^{13}$ La firma y la rúbrica de Fernán Pérez Coronel aparece en Archivo Condal de Cedillo [en adelante, ACC], caja 61, doc. 32, fechado en Guadalupe el 20 de junio de 1492, documento sobre arrendamientos de rentas y diezmos pertenecientes a la mesa arzobispal de Toledo. Fechado tan sólo cinco días tras su conversión al cristianismo es, sin duda, uno de los primeros documentos firmado por el convertido Fernán Pérez Coronel. El actual titular del archivo nos ha remitido amablemente autorización escrita para poder publicar las imágenes. 
segundas nupcias con una hija de Abraham Seneor y le acompañó desde pronto en la administración de los asuntos económicos de la compañía. Esto hizo que su patrimonio en Ávila y Segovia creciese hasta superar ampliamente los dos millones de maravedíes ${ }^{14}$. Rabí Mayr recibió el bautismo a la vez que su suegro, cuando contaba con 55 ó 60 años ${ }^{15}$, y adoptó el nombre de Fernán Núñez Coronel.

Tan sólo disponemos de la suscripción que utilizó una vez convertido al cristianismo. En ella el nombre del suscriptor está escrito también en letra cortesana, con el apellido abreviado («Fernand Nuñes») finalizando en un bucle. A la izquierda colocaba su compleja rúbrica en la que se aprecia una sucesión de bucles y tres pequeños lóbulos orientados horizontalmente hacia la izquierda:

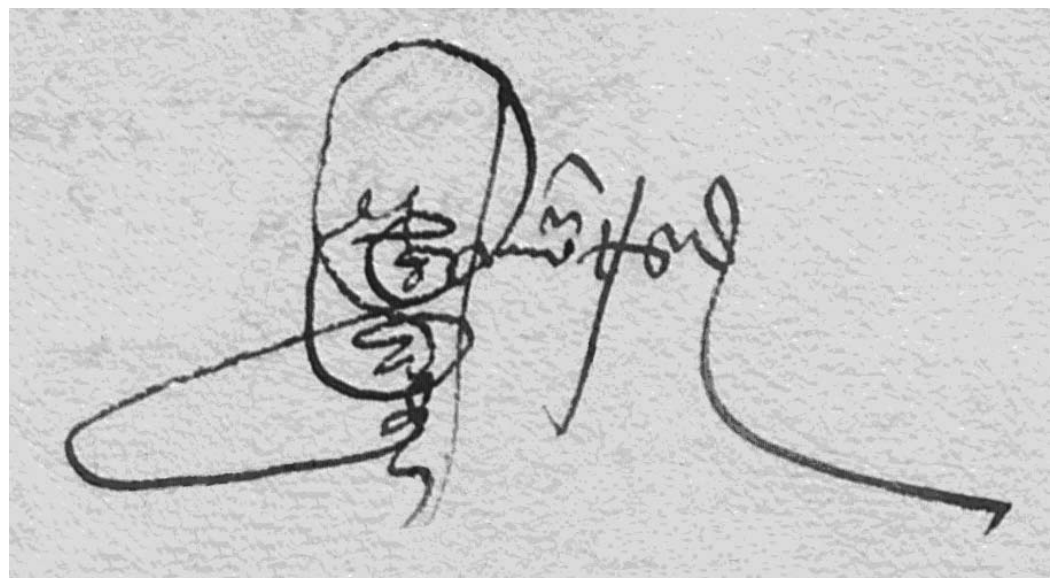

Fig. 3: Firma y rúbrica de Fernán Núñez [Coronel] ${ }^{16}$.

El último miembro permanente de la compañía fue Luis de Alcalá, vecino y regidor de Madrid. De supuesta ascendencia judía, apenas se conocen datos personales sobre él, aunque se ha podido averiguar que tuvo un extenso patrimonio

${ }^{14}$ M. Asenjo González, Segovia. La ciudad y su tierra a fines del medievo (Segovia 1986), págs. 391-393.

${ }^{15}$ Carrete Parrondo, «La hacienda castellana», pág. 342, n. 11.

${ }^{16}$ La firma y la rúbrica de Fernán Núñez Coronel aparece en ACC, caja 61, doc. 32, fechado en Guadalupe el 20 de junio de 1492, también cinco días después de su conversión. Al igual que en el caso anterior, estamos ante lo que tal vez sea el primer documento firmado por el convertido Fernán Núñez Coronel. 
en la villa de Madrid y en sus alrededores valorado en cerca de tres millones de maravedíes ${ }^{17}$.

Su firma incluye su nombre escrito en letra cortesana («Luys de Alcala») con un bucle final similar al de la firma anterior, además de una rúbrica a la izquierda compuesta por tres bucles superiores y tres inferiores:

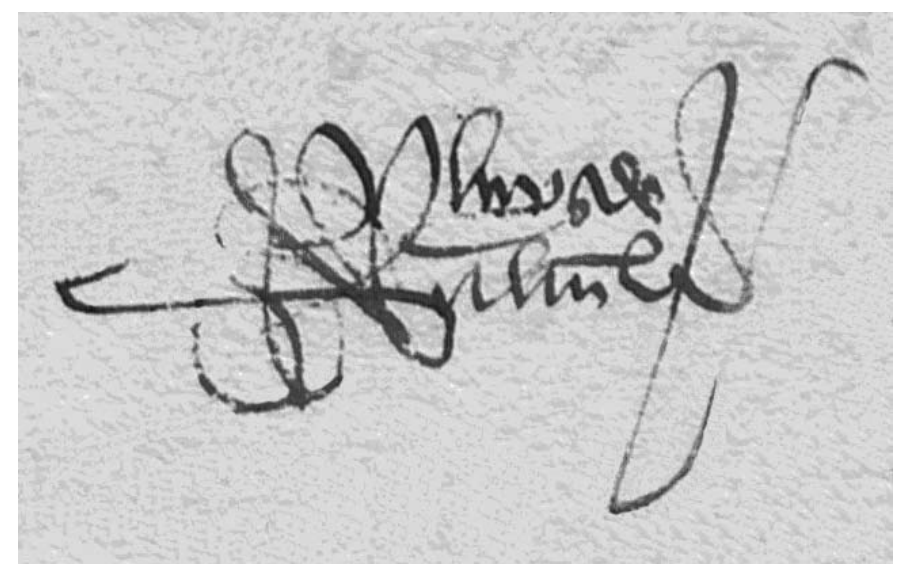

Fig. 4: Firma y rúbrica de Luis de Alcalá ${ }^{18}$.

\section{Conclusiones}

Una vez reproducidas las firmas y las rúbricas de los miembros de la compañía podemos extraer algunas conclusiones. Primeramente, el tipo de escritura utilizado en todos los casos fue la llamada letra cortesana, que se empleó en Castilla durante prácticamente todo el siglo XV y principios del XVI. Esto hacía que los firmantes tuviesen que añadir una rúbrica para personalizar su suscripción y diferenciarla de las realizadas por otros homónimos en el mismo tipo gráfico.

También hay que señalar que en el caso de Abraham Seneor se introducen en su firma caracteres en hebreo que respondían a su propio nombre en esa lengua. Esta circunstancia aportaba más originalidad y distinción a su firma, y además se convertía en un medio para consignar públicamente su confesión religiosa.

\footnotetext{
${ }^{17}$ Álvarez García, «Los judíos y la Hacienda Real», pág. 89.

${ }^{18}$ La firma y la rúbrica de Luis de Alcalá aparece en ACC, caja 61, doc. 32, fechado en Guadalupe el 20 de junio de 1492.
} 
Por último, es destacable que don Abraham Seneor mantuviera la misma rúbrica una vez convertido al cristianismo. Tras su bautismo, sólo tuvo que modificar la firma para adaptarla a su nuevo nombre. Sin duda alguna la adaptación a este cambio en la grafía de su propio nombre no debió ser sencilla, pero al menos siguió manteniendo la atractiva rúbrica por la que era reconocido por sus contemporáneos.

Ahora bien, ¿mantuvieron otros conversos la misma rúbrica que habían utilizado siendo judíos? Este interrogante habrá de ser respondido cuando aparezcan nuevas suscripciones de los numerosos judeoconversos que jalonaron la historia de España. Hasta entonces baste con esta modesta aportación a un fenómeno de mayor trascendencia y calado.

Recibido: 30/08/2010

Aceptado: 30/11/2010 